\title{
ACHIEVING SUSTAINABLE DEVELOPMENT THROUGH STRATEGIC GREEN SUPPLY CHAIN MANAGEMENT
}

\section{Dr. E. Eswara Reddy}

\author{
M.Com.m MBA.,Ph.D. Professor School Of Economics And Commerce CMR \\ University City Campus Bangalore 43
}

M.Com Research Scholar School Of Economics And Commerce CMR University City Campus Bangalore 43 Faculty Member Faculty Of Commerce And Management Sheshadripuram First Grade College Tumkur $572102{ }^{*}$ Corresponding Author

ABSTRACT Environmentally and socially responsive supply chains are in the early adoption stages in India. Global supply chains need worldwide goals, and the key to the success of Green Supply Chain Management is to bring the worldwide industry together to decide upon and pledge to work towards reasonable and concrete goals that will make a real difference to the environment. Customers are increasingly demanding to know where products come from, how they are made and distributed and what impact future environmental legislations will have on the products they buy. The aim of this paper is to provide action plans and facilitate knowledge among supply chain practitioner that they need to go green the business efficiently, and communicate these efforts to their customers, partners, and the public. In fact, the paper discusses the key drivers for green initiatives include government compliance, improved customer and public relations, a decreased fuel bill and financial ROI through various supply chain initiatives such as reverse logistics. Further, increasing supply chain efficiency, improving investor relations, decreasing risk and a larger corporate responsibility agenda are identified as important factors in the strategic decision to go green. Companies working in India are not properly addressing these measures in supply chain design and operations. That is why, the paper further elaborates strategic management of green supply chain, which involves collecting and analyzing environmental regulations and customer concerns, discussing the relevant environmental issues with the procurement, manufacturing and quality control departments across the supply chain firms and finally developing and communicating the green supply chain policies to all members of the supply chain i.e. supplier's supplier to customer's customer.

\section{KEYWORDS : Green Supply Chain, Environment, Supplier Performance Management, Holistic Approach} Sustainable Development.

\section{INTRODUCTION}

As the public becomes more aware of environmental issues and global warming, consumers will be asking more questions about the products they are purchasing. Companies will have to expect questions about how green their manufacturing processes and supply chain are, their carbon footprint and how they recycle. However some companies have seen that this not a bad thing and indeed have been able to convert the public's interest in all things green into increased profits. Environmental initiatives such as strategic environmental sourcing improve an organization's competitive position and reduce risks (Sroufe, 2003). A number of companies have shown that there is a proof of the link between improved environmental performance and financial gains. Companies have looked to their supply chain and seen areas where improvements in the way they operate can produce profits. Companies can find cost savings by reducing the environmental impact of their business processes. By re-evaluating the company's supply chain, from purchasing, planning, and managing the use of materials to shipping and distributing final products, savings are often identified as a benefit of implementing green policies Hopefully the interest in green issues and environmental concern by the public will not decrease as economic issues become more important due to the faltering economy. The trend towards developing a green supply chain is now gaining popularity but most companies are still coming to terms with how this can be achieved and where do they start. For years businesses have been concentrating on improving supply chain visibility, refining efficiency and minimizing cost. Despite the focus being moving towards a green supply chain the goals of visibility, efficiency and cost reduction do not have to be discarded.
Many businesses have not developed a successful refurbi shment program for their products that have been returned or exchanged. By offering refurbished items businesses can increase purchasing options to their customers and widen their customer base, whilst improving the environmental impact of their products. Organizations worldwide are continuously trying to develop new and innovative ways to enhance their competitiveness (Rao and Holt, 2005). Bacallan (2000) suggests that some organizations are enhancing their competitiveness through improvements in their environmental performance to comply with mounting environmental regulations, to address the environmental concerns of their customers, and to mitigate the environmental impact of their production and service activities.

\section{NEED OF GREEN SUPPLY CHAIN MANAGEMENT}

Greening the supply chain has numerous benefits to an organization, ranging from cost reduction, to integrating suppliers in a participative decision-making process that promotes environmental innovation (Bowen et al., 2001; Hall, 2003; Rao, 2002). A growing number of corporations are developing company-wide environmental programs and green products sourced from markets around the world (Min and Galle, 1997). Globally, governments are exerting pressure on businesses to do more to reduce the negative impact of operations have on the environment. Pressure is coming from the physical world too. Even if it's possible for companies to ignore the impact of their operations on environment but shortage of resources that go into products are necessary to make or move products. It is a direct threat to the success of business. Similarly, a shortage of available energy at a plant location can force companies to curtail production. In addition, many 


\section{KEY DRIVERS FOR GREEN INITIATIVES}

\section{GOVERNMENT COMPLIANCE}

The climate change is happening faster and will bring bigger changes quicker than anticipated. Ironically market and the nature hitting the wall at once, is a sign that we need to find better ways to be more sustainable. Whether the drive is to comply with the government regulations or to meet the costumers' expectations companies are finding motivation to go green. Going green does not just impact company's thinking and strategy but influences supply chain as well. Righteously the focus is not just to attain cleaner water consumption and alternative energy sources for server farms, but to make supply chains more environmentally friendly. The movement toward green and sustainable business practices is the new frontier for manufacturers and "Going Green" is the next step in the lean, just-in-time movement. There has been much reported recently in the news about the conflicting scientific data in the fight for our global ecological salvation. But for manufacturers, this should be more than a question of carbon emissions and water conservation. It is a means to reduce a significant amount of waste and cost in the manufacturing process. No government regulation requires a company to go lean, and no regulation should be required to go green either. The green/sustainability movement is about eliminating waste, reducing costs and doing business for the long haul.

\section{FINANCIAL ROI}

The business leaders steering their companies through the recession of 2009 would look at their supply chains and assess whether their use of global, open supply-chain standards is sufficient to maximize their return on investment and position themselves for profitability. The futures of their businesses may depend on it. As the recession continues into the spring of 2009, many manufacturers are responding to decreased levels of activities with trading partners not only by cutting costs, but also by curtailing their supply-chain operations and waiting for consumers and retailers to start buying again. They are incorporating a standards based approach to product identification and data capture in their "four walls" applications locally, like asset management, work-in-process flow, and yard management. More important, they are planning ahead for working with their trading partners, thinking globally by implementing data sharing with partners everywhere across their operations and supply chains, so they have actionable visibility achievable through standards.

\section{REVERSE LOGISTICS}

The purpose of the reverse logistics process is to ensure that products/materials are returned from the user to the producer in order to be recycled, reused or reconditioned. In reverse logistics the chain is covered in the opposite direction. Reverse logistics therefore denotes a set of planning, execution and flow control measures for raw materials and finished products, with the aim of recovering and recycling those products or materials. Standardized reusable containers, good warehousing layouts, and easy information access reduce storage and retrieval delays which lead to savings in operating costs whilst being environmentally sound (Wu and Dunn, 1995). Logistics involves a whole range of activities, including collection, sorting, processing and reconditioning. Returns management embraces: returns at the end of a product's life, commercial returns (leasing, mail order, B2C), contractual returns, returns under warranty (faulty goods), production waste and scraps, and "functional" returns, such as packaging to be reused for the same purpose (containers, packaging). Reverse logistics used to be the preserve of distributors of newspapers and magazines (products which have a very limited life span) and mail order distributors (covering products not wanted by consumers). Manufacturers have a variety of options to contribute to the improvement of the environment. Through proactive initiatives, current processes can be utilized to create efficiencies that both protect the environment and positively impact the bottom line. While this may seem to be a daunting task, in most cases, green initiatives can be implemented relatively easily by altering existing repair and refurbishment operations through recycling and other programs.

\section{HERE ARE SIX TIPS FOR CREATING A "GREEN" PROGRAM:}

1. Create generic, less expensive and lighter packaging for refurbished goods.

2. Utilize biodegradable packaging, made from recycled material.

3. Sort recyclable materials as specific as possible to maximize volume and revenue.

4. Work with regional recycling experts to reduce transportation costs.

5. Recycle material in a timely manner to maximize market viability.

6. Educate and encourage the entire organization to contribute to "green" causes.

\section{SUPPLY CHAIN EFFICIENCY}

Organizations are integrating their supply chains to reduce operating costs and improve their customer service (Walton et al., 1998). Companies do not often change their businesses processes and it is this attitude allows inefficient processes to continue unabated causing unnecessary waste and pollution. The most commonly perceived enemy to environmental protection is manufacturing and production operations. That is, manufacturing and production processes are viewed as the culprits in harming the environment, in the forms of waste generation, ecosystem disruption, and depletion of natural resources (Fiksel, 1996). Many companies that have been through this exercise have identified processes where raw materials were wasted; resources underutilized and unnecessary energy used due to inefficient equipment. Successful supply chain management is an iterative process that evaluates the cost/benefit trade-offs of operational components. The success of effective supply chain management is only as good as the ability to properly execute it for the benefit of all stakeholders of the supply chain. A great supply chain, linked with a process of operational excellence, can provide success for the manufacturing company and also its partners, suppliers and customers. A centralized distribution model can also create further efficiencies. While this may not be feasible for all manufacturers, centralizing operations enable asset consolidation, in addition to streamlining the test, repair and refurbishment process. Product companies can adopt a number of business strategies that serve the dual purpose of environmental stewardship and improving business results.

\section{- Adopt lean materials management.}

- Use more recycled materials.

- Redesign products to weigh less.

- Reduce packaging content.

- Model the environmental impact of your product.

- Model the health and well-being impact of your products.

- Buy local to reduce carbon footprint.

\section{CORPORATE RESPONSIBILITY}

Green initiatives are tied to the larger issue of corporate social responsibility (CSR), the idea that companies have obligations not just to their investors but also to their stakeholders, society, and the environment. Many corporations driven to comply with increasing government regulations and pressure from shareholders are turning to the International Organization for Standardization (ISO) for guidance with implementing green and CSR programs. Similar to the ISO 9000 standard for quality, the ISO 14000 standard for environmental management systems (EMS) establishes best practices and benchmarks for green 
initiatives, and the ISO 26000 standard for corporate social responsibility establishes a framework for the development of CSR standards. Government agencies and companies concerned with sustainability issues will adopt these standards and ask their suppliers and vendors to follow suit. The green strategy is also aligned with the government contract compliance initiatives and company's corporate social responsibility initiatives. Today the mission of each firm is to operate their business in the most environmentallyfriendly way. This includes:

- Establishing a green product offering from key vendors for national distribution and clearly identifying those products in their marketing materials, including their catalog and web site.

- Purchasing green products from their suppliers.

- Reducing waste and recycling \& reusing materials at every opportunity.

- Reducing their electrical energy consumption.

- Designing distribution routes to minimize fuel consu mption.

- Encouraging car pooling and responsible business travel.

- Repairing rather than throwing away whenever possible.

- Receiving electronic POs, invoices, and other business documents from vendors and customers whenever possible.

- Encouraging their customers to sign up for Electronic Invoicing via fax, email, or the web to reduce paper usage

\section{GAINING SUSTAINABILITY THROUGH GREEN SUPPLY CHAIN MANAGEMENT}

Sustainable development is development that meets the needs of the present without compromising the ability of future generations to meet their own needs. Implementing a sustainable development approach within a company is a horizontal task, inasmuch as it impacts on almost all the company's functions. Green is a subset of the broader world of sustainability. Sustainability incorporates endeavors such as fair labor practices, human rights, and community responsibility, while green includes things that impact the environment. Companies are considering redesigning their long and complex supply chains to reduce transportation costs and the associated carbon footprint generated by moving goods long distances. In the next several years we will be hearing more about Supply Chain Sustainability or the Green Sustainable Supply Chain. A Green Sustainable Supply Chain can be defined as "the process of using environmentally friendly inputs and transforming these inputs through change agents whose byproducts can improve or be recycled within the existing environment. This process develops outputs that can be reclaimed and re-used at the end of their life-cycle thus, creating a sustainable supply chain." The whole idea of a sustainable supply chain is to reduce costs while helping the environment. Many people would argue that being environmentally friendly increases your costs.

\section{CONCLUSION}

Businesses can position themselves anywhere along the spectrum of the green chain, from complying with regulations and choosing equipment like bio-diesel engines or lowenergy-consuming light bulbs for their facilities. They can position themselves to move ahead of the curve and be at the forefront in shaping and fixing the environment by redesigning the overall network by pushing for new regulations, developing new products, and beginning to redesign their supply chains to include suppliers and transportation mode selections. There are many ways in which businesses can transit to a green supply chain; however, it is important to realize that it is difficult to achieve results without strong focused leadership. Senior manag ement has to lead the effort to move towards a green supply chain and provide the resources for the transition. Many businesses have documented an intent or plan to implement a green supply chain, but without the necessary resources, both financial and manpower, any impact will be minimal. In the future, companies will be moving to a sustainable supply chain. The harsh reality is that we need to change what we are doing from a supply chain standpoint in order to ensure that future generations will have resources to use in their lifetime. The benefit of implementing a green sustainable supply chain is that we can improve the profitability of our company and help the environment. Green can not only be profitable but also become necessity to pay our dues for the concern of environment at large. Being at one end or the other of the spectrum is not necessarily good or bad, it is just different depending on the dynamics of a particular business.

\section{REFERENCES}

1. Bacallan, J.J. (2000) Greening the supply chain', Business and Environment, Vol. 6 No. 5, pp. 11-12

2. Bowen, F.E., Cousins, P.D., Lamming, R.C. and Faruk, A.C. (2001) Horses for courses: explaining the gap between the theory and practice of green supply', Greener Management International Autumn, pp. 4l-60.

3. Fiksel, J. (1996) Design for Environment: Creating Eco- Efficient Products and Processes', McGraw-Hill, New York, NY

4. Hall, J. (2003) Environmental supply chain innovation', Greening of the Supply Chain, Greenleaf.

5. Min, H. and Galle, W. (1997) Green purchasing strategies: trends and implications', International Journal of Purchasing and Materials Management, Vol. 4, pp. 10-17.

6. Rao, P. (2002) Greening of the supply chain: a new initiative in South East Asia', International Journal of Operations \& Production Management, Vol. 22 No. 6, pp. 632-55

7. Rao, P. and Holt, D. (2005) Do green supply chains lead to competitiveness and economic performance? International Journal of Operations \& Production Management Vol. 25 No. 9, pp. 898-916.

8. Sroufe, R. (2003) A framework for strategic environmental sourcing', Greening the Supply Chain, Greenleaf, Sheffield.

9. Walton, S.V., Handfield, R.B., Melnyk, S.T. (1998) The green supply chain integrating suppliers into environmental management process', International Journal of Purchasing and Materials Management, Spring, pp. 2- 11.

10. Wu, H.J. and Dunn, S.C. (1995) Environmentally responsible logistics systems', International Journal of Physical Distribution \& Logistics Management, Vol. 25 No. 2, pp. 20-38. 